\title{
Perawatan Maloklusi Angle Kelas I disertai Impaksi Kaninus Maksila Menggunakan Alat Cekat Begg
}

\author{
Darmayanti Dian Suryani, Sri Suparwitri, dan Soekarsono Hardjono \\ Program Studi Ortodonsia, PPDGS, Fakultas Kedokteran Gigi, Universitas Gadjah Mada \\ JI Denta No 1 Sekip Utara, Yogyakarta, Indonesia; e-mail: darmayanti.ortho@gmail.com
}

\begin{abstract}
ABSTRAK
Gigi kaninus sangat penting untuk estetika dan fungsi mastikasi seseorang. Impaksi gigi adalah gagalnya gigi untuk muncul ke dalam lengkung gigi yang dapat disebabkan karena kekurangan ruang, adanya sesuatu yang menghalangi jalur erupsi gigi atau karena faktor keturunan. Prevalensi impaks gigi kaninus maksila adalah 0,9-2,2\%, sedangkan impaksi gigi kaninus mandibula lebih jarang terjadi. Alternatif perawatan gigi impaksi kaninus maksila adalah operasi exposure dan diikuti dengan kekuatan ortodontik untuk membantu erupsi dengan alat cekat ortodontik. Tujuan dari perawatan adalah untuk koreksi malrelasi dan malposisi gigi geligi, khususnya koreksi gigi kaninus impaksi menggunakan teknik Begg. Pasien laki-laki, 19 tahun, gigi sangat berjejal, gigi kaninus kanan kiri rahang atas dan gigi kaninus kanan rahang bawah impaksi, kelas I, deep overbite, overjet $3 \mathrm{~mm}$ dan overbite $8,8 \mathrm{~mm}$. Perawatan dilakukan dengan menggunakan alat cekat Begg dengan tanpa pencabutan. Operasi exposure dilakukan untuk membuka gigi kaninus kanan kiri atas yang impaksi yang diikuti perekatan braket ortodontik. Kawat busur multiloop, anchorage bend dan elastik intermaksiler klas II digunakan pada tahap leveling dan unraveling. Dalam waktu 14 bulan,overbite terkoreksi, gigi kaninus kanan kiri atas sudah erupsi, overjet $3,00 \mathrm{~mm}$, overbite $3,00 \mathrm{~mm}$. Saat ini perawatan masih berlangsung pada tahap leveling dan unraveling untuk koreksi kaninus yang impaksi. Perawatan maloklusi angle klas I dengan berjejal dan impaksi kaninus maksila dapat dilakukan dengan operasi exposure gigi kaninus impaksi diikuti alat cekat Begg.
\end{abstract}

Maj Ked Gi. Desember 2014; 21(2): 184 - 190

Kata kunci: impaksi kaninus, operasi exposure, alat cekat Begg

\begin{abstract}
Orthodontic Treatment of Class I Malocclussion with Canine Impaction Using Begg Fixed Appliance. Canine is very important for aesthetic and masticatory function. Impaction refers to a failure of tooth to presence into the dental arch, usually due to either space deficiencies, the presence of an entity blocking the path of tooth eruption or due to hereditary factors. Prevalence of maxillary canines impaction is 0.9 to $2.2 \%$, while the mandibular canine impaction is less common. Alternative dental care is impacted maxillary canine exposure surgery and followed by orthodontic force for help the eruption with fixed orthodontic appliance. The goal of treatment is to correct malrelation and malposition of teeth. Patient man, 19 years old, very crowded teeth, maxillary right and left canine and mandibular right canine impaction, Angle Class I, deep overbite, $3 \mathrm{~mm}$ overjet and overbite $8,8 \mathrm{~mm}$. Treatments performed using Begg fixed appliances without extraction. Exposure surgery is done under the right and left maxillary canine impaction followed orthodontic bracket bonding. Multiloop arch wire, bend and elastic anchorage intermaksiler class II used at the stage of leveling and unraveling. Within 14 months, overbite was corrected, maxillaryr right and left canine eruption, Angle Class I canine relationship, $3.00 \mathrm{~mm}$ overjet, $3,00 \mathrm{~mm}$ overbite. Current treatment is still ongoing at leveling and unraveling stage. Treatment angle malocclusion class I with maxillary canine impaction can be done by exposure surgery followed by Begg fixed appliances.
\end{abstract}

Maj Ked Gi. Desember 2014; 21(2): 184 - 190

Keywords: canine impaction, operating exposure, Begg fixed appliances

\section{PENDAHULUAN}

Maloklusi adalah penyimpangan letak gigi dan atau malrelasi lengkung gigi (rahang) diluar rentang kewajaran yang dapat diterima. ${ }^{1}$ Maloklusi juga dapat didefinisikan sebagai keadaan yang menyimpang dari oklusi normal. ${ }^{2}$ Berbagai faktor yang mempengaruhi oklusi adalah 1) ukuran maksila dan mandibula, 2) relasi maksila dan mandibula, 3) jumlah, ukuran, dan morfologi gigi, serta 4) morfologi dan sifat jaringan lunak (bibir, lidah, dan pipi). ${ }^{3}$ Kelainan pada komponen tersebut serta interaksinya dapat menyebabkan maloklusi. ${ }^{1}$

Maloklusi Angle klas I merupakan suatu kondisi oklusi molar pertama dengan posisi tonjol mesiobukal molar pertama maksila berkontak pada groove bukal molar pertama mandibula. ${ }^{3}$ Pola 
skeletal maloklusi Angle klas I biasanya klas I tetapi dapat juga kelas II atau kelas III ringan. Maloklusi klas I dapat disertai berbagai macam malrelasi, maloklusi gigi individual, dan anomali gigi yang disebabkan oleh faktor lokal berupa diskrepansi ukuran gigi dan atau lengkung geligi. ${ }^{1}$

Gigi geligi dalam rongga mulut akan mengalami erupsi menurut urutan waktu erupsi masingmasing jenis gigi, mulai dari fase gigi sulung sampai mengalami pergantian menjadi fase gigi permanen. Proses erupsi gigi baik pada fase gigi sulung maupun permanen akan terjadi secara fisiologis dan jarang sekali mengalami gangguan. Gangguan erupsi pada umumnya terjadi pada fase pergantian dari gigi sulung menuju fase gigi permanen, sehingga gigi permanen tertentu tidak dapat mengalami erupsi. ${ }^{4}$

Impaksi gigi adalah gagalnya gigi untuk muncul ke dalam lengkung gigi yang dapat disebabkan karena kekurangan ruang, adanya sesuatu yang menghalangi jalur erupsi gigi atau karena faktor keturunan. ${ }^{5}$ Gigi yang paling sering mengalami impaksi pada regio anterior mulut adalah kaninus maksila. ${ }^{6}$ Prevalensi impaksi gigi kaninus maksila adalah 0,9-2,2\%,.7,9 Impaksi kaninus maksila terjadi kurang dari $2 \%$ populasi dan lebih sering terjadi pada perempuan. ${ }^{10.11}$ Kurang lebih sepertiga kasus kaninus maksila impaksi mempunyai lokasi di labial dan duapertiga lainnya berlokasi di palatal. ${ }^{12}$

Impaksi kaninus mandibula lebih banyak terdapat pada sisi labial lengkung gigi dari pada pada gigi kaninus maksila. ${ }^{13}$

Impaksi kaninus dapat disebabkan oleh berbagai macam faktor. Impaksi pada sisi palatal berkaitan dengan berbagai anomali dental seperti anomali insisivus lateral atas, aplasia, dan impaksi gigi-gigi yang lain. ${ }^{14}$ Impaksi kaninus pada sisi labial menunjukkan adanya defisiensi panjang lengkung maksila. ${ }^{11}$ Resopsi akar gigi tetangga, waktu perawatan yang lebih lama, dan hasil yang kurang memuaskan secara estetis berkaitan dengan kaninus maksila impaksi. ${ }^{13,15}$

Perawatan kaninus impaksi bervariasi tergantung pada keadaan klinis. Ekstraksi kaninus desidui, ekspansi lengkung gigi atau area lokal, atau dilakukan exposure dan atau ekstraksi dan ekspansi bertujuan untuk memberi ruang bagi erupsi kaninus. ${ }^{11}$ Terdapat 3 teknik exposure kaninus maksila impaksi yaitu excisional uncovering, apically positioned flap, dan closed eruption technique. tarikan secara mekanika ortodontik untuk proses erupsi gigi menyerupai normal dan memposisikan gigi dalam lengkung gigi sehingga diperoleh hubungan gingiva labial yang normal. ${ }^{15}$

Waktu perawatan ortodontik, tipe prosedur operasi untuk exposure gigi, alat ortodontik yang digunakan dan potensi masalah bergantung pada gigi yang impaksi dan posisi gigi tersebut di dalam rahang. ${ }^{16}$

Perawatan ortodontik bertujuan memperbaiki estetik dan fungsi regio orofasial serta kestabilan hasil perawatan. ${ }^{3,16}$ Perbaikan tersebut dihasilkan oleh penggunaan alat ortodontik yang dengan tekanan ringan diaplikasikan ke gigi, kelompok gigi, dan jaringan pendukungnya sehingga menghasilkan perubahan tulang untuk menggerakkan gigi atau memodifikasi pertumbuhan rahang. ${ }^{17}$ Maloklusi Angle klas I dapat dirawat dengan alat cekat teknik Begg. Perawatan teknik Begg menggunakan kawat busur berpenampang bulat dan braket yang keduanya menghasilkan titik kontak tunggal sehingga gigi bergerak secara tipping. Kawat busur dilengkapi dengan loop vertikal, circle hook, anchorage bend, dan berbagai alat tambahan seperti rotating spring, uprighting spring, dan torquing arch. Pengurangan overbite disebabkan gerakan resiprokal gigi molar mandibula dan anchorage bend sehingga mengakibatkan gaya intrusi gigi-gigi anterior. Komponen gaya vertikal elastik intermaksiler klas II membantu memberikan elevasi gigi molar mandibula sehingga menambah gaya depresi pada gigi insisivus mandibula juga intrusi gigi anterior maksila. ${ }^{18,19}$

Tujuan laporan kasus ini adalah untuk memberikan informasi mengenai bagaimana perawatan pasien dengan impaksi gigi kaninus maksila dengan menggunakan alat cekat sistem Begg. Publikasi kasus ini telah disetujui oleh pasien secara lisan. 

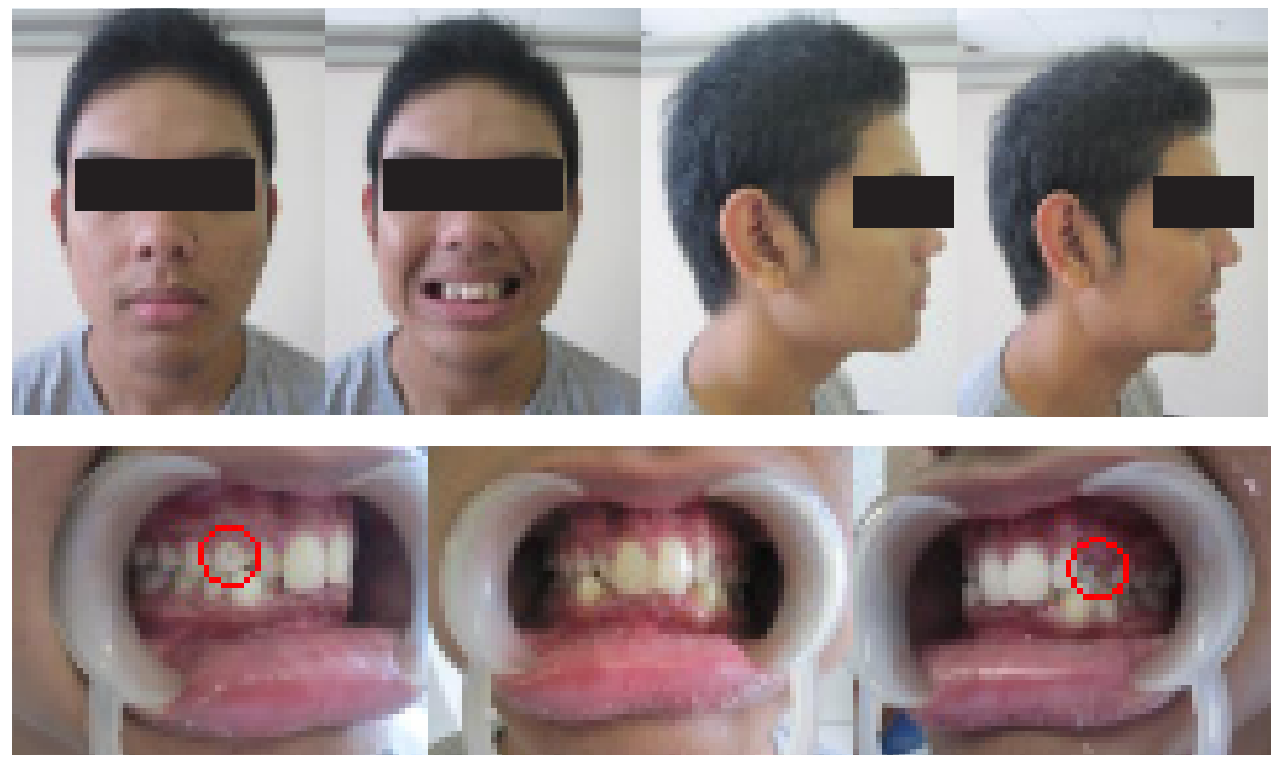

Gambar 1. Foto intraoral dan ekstraoral sebelum perawatan,tampak gigi kaninus permanen belum erupsi, dan gigi kaninus desidui belum tanggal

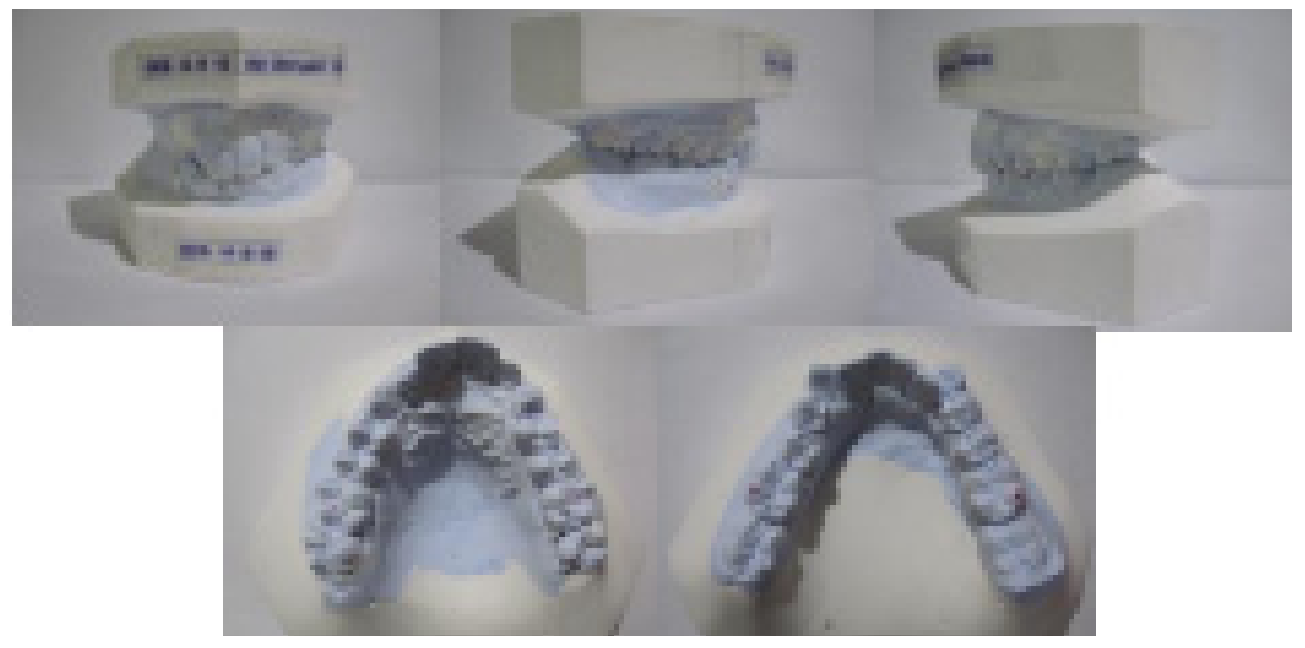

Gambar 2. Foto model gigi sebelum perawatan

\section{METODE}

Pasien laki-laki, 19 tahun, datang ke Klinik Ortodonsia RSGM Prof.Soedomo dengan keluhan gigi berjejal. Pemeriksaan intra oral menunjukkan maloklusi Angle kelas I, gigi kaninus kanan kiri rahang atas dan gigi kaninus kanan rahang bawah tidak erupsi dan gigi kaninus desidui masih melekat kuat pada posisinya, gigi anterior rahang atas dan rahang bawah sangat berjejal, kurve spee rahang bawah tajam, deep overbite, overjet $3 \mathrm{~mm}$ dan overbite $8,80 \mathrm{~mm}$ (Gambar 1 dan 2)
Analisis radiografi panoramik menunjukkan gigi kaninus kanan rahang bawah impaksi dengan posisi horizontal, kaninus rahang atas kanan dan kiri posisi apeks ada di bawah apeks premolar pertama sedangkan bagian mahkota berada di antara gigi insisivus pertama dan kedua. Foto shift sketch (Gambar 3) menunjukkan gigi kaninus kanan dan kiri rahang atas impaksi dengan posisi di palatal, sedangkan gigi kaninus kanan rahang bawah impaksi dengan posisi di bukal. Tracing radiografi sefalometri menunjukkan hubungan skeletal klas I. 


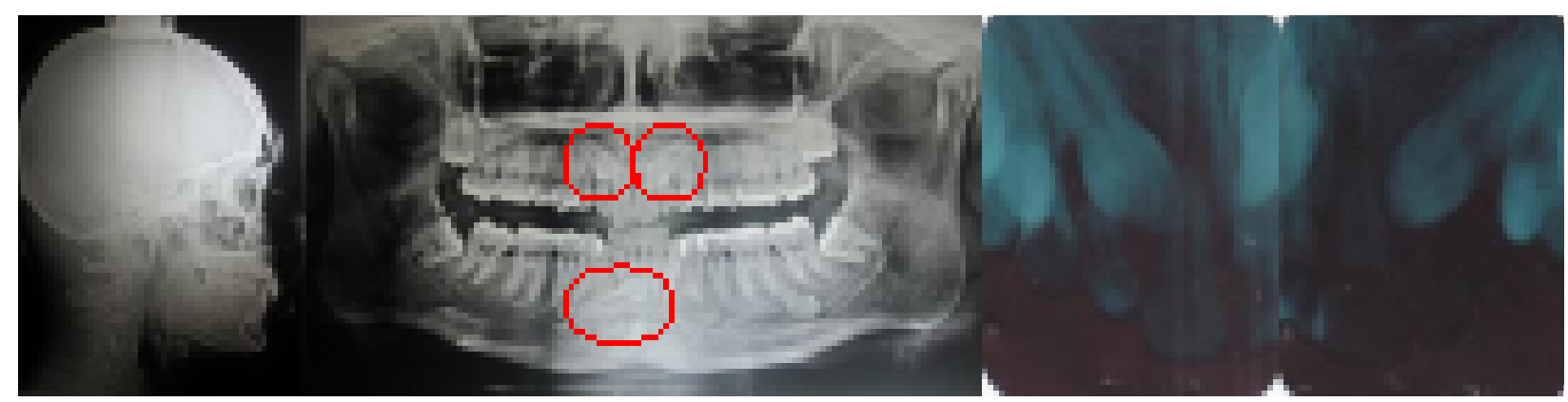

Gambar 3. Radiografi sebelum perawatan, gigi kaninus permanen kanan kiri atas dan kanan bawah impaksi

Diagnosis maloklusi Angle kelas I dengan skeletal kelas I pergeseran midline gigi rahang bawah ke kanan sebesar $2,9 \mathrm{~mm}$, crossbite, deep overbite, crowded, impaksi gigi kaninus kanan kiri maksila dan kaninus kanan mandibula. Tujuan perawatan kasus ini adalah mengoreksi gigi kaninus kanan kiri rahang atas yang impaksi dan mengatur gigi geligi dalam lengkung yang baik, mengoreksi malposisi dan malrelasi.

Tujuan perawatan dijelaskan kepada pasien, yaitu menarik gigi kaninus kanan kiri rahang atas yang impaksi untuk erupsi dan mengambil gigi kaninus kanan yang impaksi dengan posisi horizontal yang tidak mungkin dilakukan perawatan ortodontik, mengoreksi crowding, deepbite, dan mempertahankan relasi molar pertama kanan klas I. Rencana perawatan dilakukan perawatan alat cekat teknik Begg dengan pencabutan gigi kaninus desidui, exposure gigi 13 dan 23 yang impaksi. Berdasarkan perhitungan determinasi lengkung dan set up model Kesling masih dibutuhkan ruang sebesar 5,6 mm untuk maksila dan 10,6 $\mathrm{mm}$ pada mandibula. Kekurangan ruang pada maksila diperoleh melalui ekspansi, sedangkan pada mandibular diperoleh melalui pencabutan gigi kaninus desidui dan ekspansi. Perawatan dilakukan dengan alat cekat teknik Begg.

Perawatan teknik Begg dilakukan dalam 3 tahap. Perawatan tahap pertama bertujuan untuk general alignment, leveling dan unraveling, serta koreksi deepbite. Pada tahap ini digunakan archwire 0,014" dengan multiple vertical loop dilengkapi circle hook, anchorage bend $45^{\circ}$, dan elastik intermaksiler klas II 5/16" 2 oz. Perawatan dilanjutkan dengan penggunaan archwire 0,016" dengan $v$ bend pada mesial braket 14 dan 24 untuk menjaga ruang bekas pencabutan gigi desidui untuk ruang erupsinya gigi 13 dan 14 , disertai anchorage bend $30^{\circ}$, elastik intermaksiler klas II 5/16" 2 oz.

Perawatantahap kedua bertujuan mempertahankan hasil perawatan tahap pertama dan penutupan sisa ruang pencabutan dengan mesialisasi gigi posterior. Pada kasus ini tidak dilakukan perawatan tahap kedua karena tidak adanya pencabutan gigi permanen dan tidak terdapat sisa ruang.

Perawatan tahap ketiga bertujuan mengoreksi inklinasi gigi-gigi anterior dan posterior. Pada tahap ini digunakan plain archwire 0,020", anchorage bend $15^{\circ}$, circle hook pada mesial braket kaninus, uprighting spring, rotating spring, elastik intermaksiler klas II 5/16" 2 oz untuk mempertahankan relasi molar yang telah dicapai, dan cinched back wire di distal molar tube untuk mempertahankan panjang lengkung gigi.

Ligasi wire 0,001" pada braket gigi kaninus ke arch wire dengan arah tarikan lebih ke arah distal untuk mengarahkan gigi kaninus impaksi yang condong ke arah akar gigi insisifus lateral kanan rahang bawah. Ligasi wire 0,01" diputar tiap kali kontrol untuk memberikan tarikan pada gigi kaninus yang impaksi menuju lengkung gigi, setelah erupsi kemudian braket diikatkanpada arch wire hingga mencapai level yang sama.

\section{PEMBAHASAN}

Kaninus maksila impaksi dapat terjadi karena kegagalan resorpsi gigi desidui sehingga gigi 
Tabel 1.Pengukuran sefalometri sebelum perawatan dan selama perawatan.

\begin{tabular}{lccc}
\hline Pengukuran & Nilai normal & Sebelum Perawatan & SelamaPerawatan \\
\hline Facial angle & $82^{\circ}-95^{\circ}$ & $89^{\circ}$ & $88^{\circ}$ \\
Angle of convexcity & $-8,5^{\circ}-9^{\circ}$ & $-2,5^{\circ}$ & $+5^{\circ}$ \\
Bidang A-B & $-9^{\circ}-0^{\circ}$ & $-1^{\circ}$ & $-9^{\circ}$ \\
FMPA & $17^{\circ}-28^{\circ}$ & $12^{\circ}$ & $14^{\circ}$ \\
Y-axis & $53^{\circ}-66^{\circ}$ & $59^{\circ}$ & $60^{\circ}$ \\
SNA & $82^{\circ}$ & $78^{\circ}$ & $80^{\circ}$ \\
SNB & $80^{\circ}$ & $78^{\circ}$ & $76^{\circ}$ \\
ANB & $2^{\circ}$ & $0^{\circ}$ & $4^{\circ}$ \\
GoGn-SN & $32^{\circ}$ & $22^{\circ}$ & $24^{\circ}$ \\
Inter I-I & $130^{\circ}$ & $148^{\circ}$ & $140^{\circ}$ \\
Sudut I-NA & $22^{\circ}$ & $19^{\circ}$ & $18^{\circ}$ \\
I-NA (mm) & $4 \mathrm{~mm}$ & $9 \mathrm{~mm}$ & $4 \mathrm{~mm}$ \\
Sudut I-NB & $25^{\circ}$ & $12^{\circ}$ & $10^{\circ}$ \\
I-NB (mm) & $4 \mathrm{~mm}$ & $3 \mathrm{~mm}$ & $3 \mathrm{~mm}$ \\
IMPA & $81,5^{\circ}-97^{\circ}$ & $90^{\circ}$ & $96^{\circ}$ \\
Occ. PI.-SN & $14^{\circ}$ & $14^{\circ}$ & $18^{\circ}$ \\
Occ. PI.-FHP & $1,5^{\circ}-14,3^{\circ}$ & $4^{\circ}$ & $7^{\circ}$ \\
Overbite & $2-4 \mathrm{~mm}$ & $3,00 \mathrm{~mm}$ & $3,00 \mathrm{~mm}$ \\
Overjet & $2-4 \mathrm{~mm}$ & $8,80 \mathrm{~mm}$ & $3,00 \mathrm{~mm}$ \\
\hline
\end{tabular}

desidui menjadi persistensi, hal ini menimbulkan kegagalan gigi permanen untuk bererupsi sehingga gigi permanen menjadi terpendam. ${ }^{5}$ Pada kasus ini posisi kaninus maksila impaksi berada pada sisi palatal yang ditunjukkan oleh hasil pemeriksaan rontgen Shift sketch menggunakan dua film periapikal. ${ }^{9}$ Perawatan kaninus maksila impaksi dilakukan exposure dengan closed eruption technique kemudian menarik gigi kaninus impaksi secara bertahap dengan mekanika perawatan ortodontik sampai gigi tersebut mencapai garis oklusi dan menempati ruang yang disediakan oleh pencabutan gigi kaninus desidui maksila.

Perawatan tahap pertama alat cekat sistem Begg bertujuan untuk levelling, unraveling, dan bite opening. ${ }^{14}$ Gigi kaninus maksila impaksi yang telah dilakukan exposure ditarik secara bertahap sehingga mencapai garis oklusi dan menempati posisinya dalam legkung gigi. Pada tahap ini digunakan archwire 0,014" dilengkapi vertical loop, circle hook, anchorage bend $45^{\circ}$, dan elastik intermaksiler klas II 5/16" 2 oz. Perubahan yang dapat diamati saat ini adalah kaninus maksila impaksi telah erupsi, crowding dental maksila dan mandibula telah terkoreksi, overjet $3 \mathrm{~mm}$, dan overbite $3 \mathrm{~mm}$ (gambar 5 dan gambar 6). Keadaan skeletal pasien menunjukkan adanya perubahan namun masih tetap dalam relasi klas I dengan dental normal (gambar 7 dan tabel 1). Hal ini tidak sesuai dengan rencana perawatan bahwa tidak dilakukan perubahan skeletal. Perubahan tampak pada analisis skeletal, SNA (berubah mendekati nilai normal sebesar $2^{\circ}$ menjadi $80^{\circ}$ ), sedangkan SNB (berubah menjauhi nilai normal sebesar $2^{\circ}$ menjadi $76^{\circ}$ ), ini menyebabkan ANB menjadi besar $\left(4^{\circ}\right)$ sehingga terjadi perubahan skeletal menjadi klas II (Tabel 1). Hal ini kemungkinan disebabkan karena terjadinya kesalahan diagnosis pada saat akan dilakukan odontektomi untuk mengambil gigi 43 yang impaksi dengan posisi horizontal. Hasil foto rontgen shift sketch menunjukkan impaksi terletak pada sisi labial. Ketika dilakukan pembedahan pada sisi labial tidak ditemukan adanya gigi 43 tersebut dan pada akhirnya dilakukan pembedahan pada sisi lingual. Perubahan ini kemungkinan disebabkan karena perubahan titik $B$, karena pada saat pembedahan telah dilakukan pengurangan tulang pada sisi labial dan regenerasi tulang tidak bisa sesuai dengan keadaan tulang semula. 


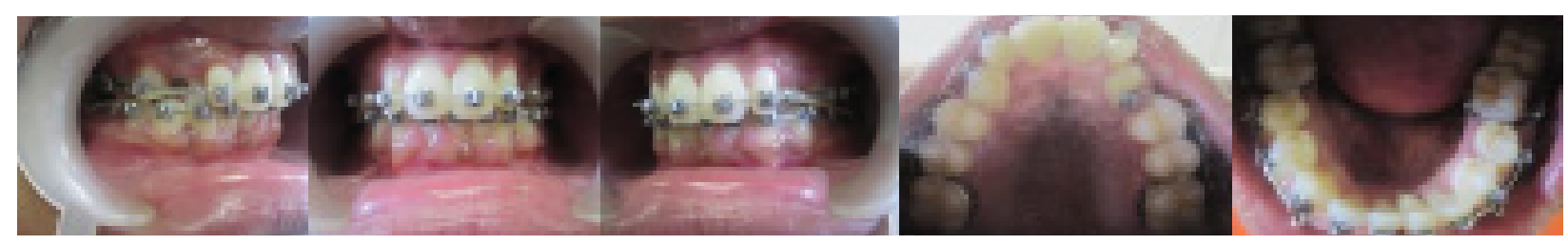

Gambar 4. Foto intra selama perawatan
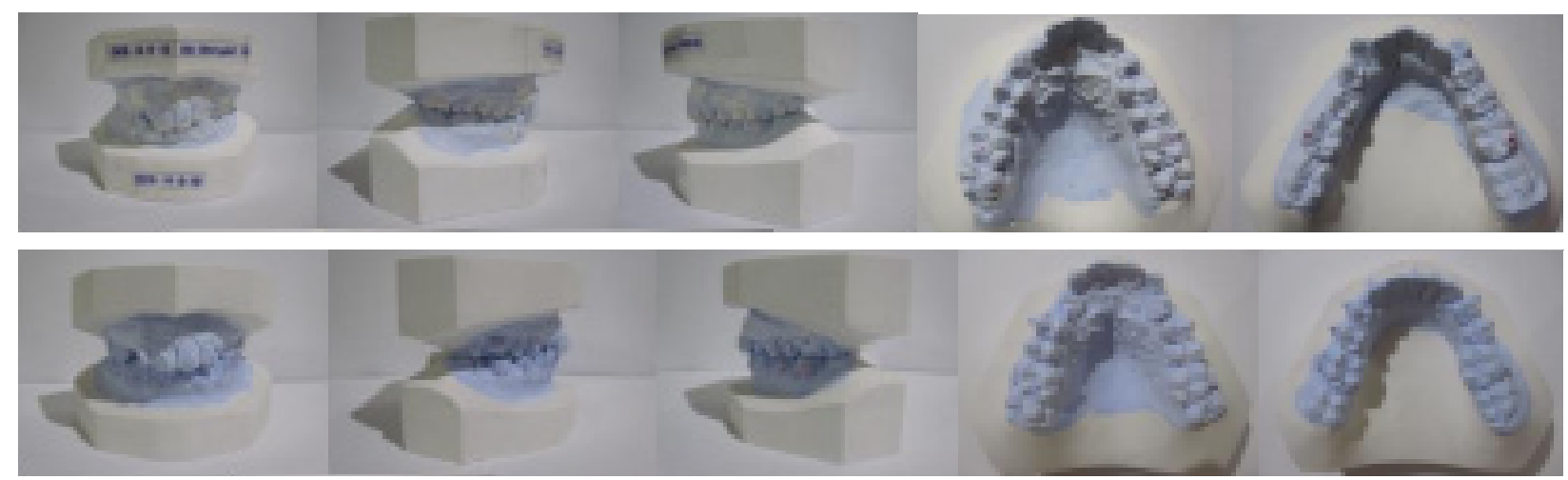

Gambar 5. Foto model gigi sebelum dan selama perawatan (16 bulan)

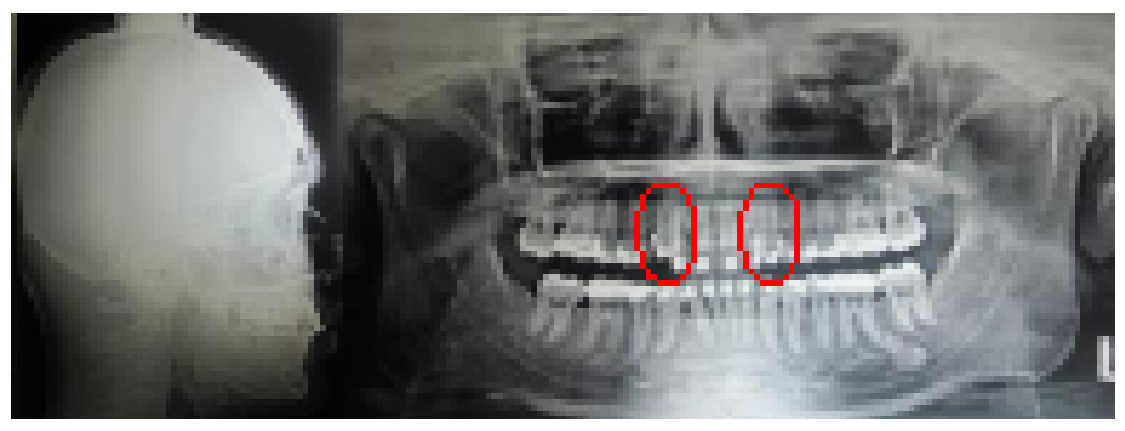

Gambar 6. Rontgen foto selama perawatan, gigi kaninus permanen sudah berada pada posisi yang tepat

Gambaran rontgen menunjukkan bahwa gigi 13 dan 14 sudah mulai menempati posisinya (Gambar 6).Perawatan saat ini dalam tahap menarik kaninus untuk menempati posisinya dan melebarkan lengkung rahang atas untuk mendapatkan ruang menggunakan plain archwire 0,016" dilengkapi circle hook, anchorage bend $15^{\circ}$, elastik intermaksiler klas II 5/16" 2 oz serta uprighting spring untuk gigi anterior rahang bawah.

\section{KESIMPULAN}

Perawataan kaninus impaksi labial pada kasus ini dilakukan exposure dengan closed eruption technique kemudian dilanjutkan tarikan secara mekanika ortodontik menggunakan teknik Begg dapat memberikan hasil yang memuaskan.

\section{DAFTAR PUSTAKA}

1. Susilowati S. Korelasi antara lebar mesiodistal gigi dengan kecembungan profil jaringan lunak wajah orang bugis-makassar. Dentofacial. 2007 Okt; 2(6): 73

2. Mavreas D., Athanasiou AE. Factor affecting the duration of orthodontic treatment: a systemic review.University of theddoloniki. 2008 Des; 30:387, 393 
3. lyyer, BS. Orthodontics The Art and Science. $3^{\text {rd }}$ ed. New Delhi: Arya (MEDI) Publishing House; 2004.

4. Milberg DJ. Labially impacted maxillary canines causing severe root resoprtion of maxillary central incisors. Angle Orthod. 2006; 76:173-6.

5. Smith B, Stewart K, Liu S, Eckert G, Kula K. Prediction of orthodontic treatment of surgically exposed unilateral maxillary impacted canine patients. Angle Orthod. 2012; 82: 723-31.

6. Manne R, Gandikota CS, Juvvadi SR, Rama HRM, Anche S. Impacted canines: Etiology, diagnosis, and orthodontic management. J Pharm Bioallied Sci. Agustus 2012; 4(Suppl 2): 234-38

7. D'Amico RM, Bjerklin K, Kurol J, Falahat B. Long-term Results of Orthodontic Treatment of Impacted Maxillary Canines. Angle Orthod. 2003; 73:231-238.

8. Monika, R, Mahesh G, Nikhil M. Bilateral Mandibular Canine Impaction: A Rare Case Report. JOHCD. May 2009; 3(2): 38-41

9. Mc Donald F, Yap WL. The surgical exposure anda application of direct traction of unerupted teeth. Am J Orthod. 1986; 89:331-340

10. D'Amico RM, Bjerklin K, Kurol J, Falahat B. Long-term Results of Orthodontic Treatment of Impacted Maxillary Canines. Angle Orthod. 2003; 73:231-238.

11. Aydin U, Yilmaz HH, Yildirim D. Incidence of canine impaction and transmigration in a patient population. Dentomaxillofac Radiol. 2004;33:164-9.
12. Alaejos-Algarra C, Berini-Aytes L, GayEscoda C. Transmigration of mandibular canines: Report of six cases and review of the literature. Quintessence Int. 1998; 29:395398.

13. Becker A, Chaushu S. Success rate and duration of orthodontic treatment for adult patients with palatally impacted maxillary canines. Am J Orthod Dentofacial Orthop. 2003; 124:509-14.

14. Leifert $\mathrm{S}$, Jonas IE. Dental anomalies as a microsymptom of palatal canine displacement. J Orofac Orthop. 2003; 64:108-20.

15. Kokich VG. Surgical a $\mathrm{n} d$ orthodontic management of impacted maxillary canines. Am J Orthod Dentofacial Orthop. 2004; 126:278-83.

16. Whittington, B and Durward, C. Survey of Anomalies in Primary Teeth and Their Correlation with the Permanent Dentition. New Zealand Dental J. 1996; 92:4-8.

17. Olive RJ. Orthodontic treatment of palatally impacted maxillary canines. Aust Orthod J. 2002; 18:64-70.

18. Graber TM, Vanarsdall RL. Orthodontics, Current Principles and Techniques. $4^{\text {th }}$ ed. St. Louis: Mosby ; 2005.

19. Begg PR, Kesling PC. Begg Orthodontic Theory and Technique. $2^{\text {nd }}$ ed. Philadelphia: WB Saunders Co; 1977. 